\title{
Parental age and developmental milestones: pilot study indicated a role in understanding ADHD severity in Indian probands
}

\author{
Subhamita Maitra ${ }^{1,2}$ and Kanchan Mukhopadhyay ${ }^{1 *}$ (D)
}

\begin{abstract}
Background: In different ethnic groups, birth related factors have shown significant influence in the etiology of Attention deficit hyperactivity disorder (ADHD). Based on these interesting findings, we aimed to investigate association between different pre- and post natal variables and ADHD associated traits in Indian subjects.

Methods: ADHD Probands recruited based on the DSM-IV, were assessed by the Conner's Parent Rating Scale for behavioral problem (BPr), inattention (IA), hyperactivity (HA) and ADHD index (AI). Impulsivity (Imp) was assessed by the Tsukuyama scale.

Results: Higher paternal (Std $\beta=0.23$ ) and lower maternal (Std $\beta=0.21)$ age showed significant association with Imp of the probands. Higher paternal age also revealed association with $B \operatorname{Pr}(S \operatorname{td} \beta=0.18$ ). Age of onset was distinctly associated with $\mathrm{Al}(\mathrm{Std} \beta<0.16)$ while developmental delay was negatively correlated with BPr, Imp, IA and birth weight $(r<-0.13)$; also confirmed by Posthoc-ANOVA $(P<0.05)$.

Conclusion: We infer that parental age, developmental delay and birth related variables may have a cumulative effect on ADHD symptom severity.
\end{abstract}

Keywords: ADHD, Birth history, Developmental milestone, Behavioral problem, Inattention, Impulsivity

\section{Background}

Attention Deficit Hyperactivity Disorder (ADHD) is a neuro-developmental disorder, mostly detected in school-going children/adolescents [1, 2]. Apart from the cardinal symptoms of age inappropriate inattention (IA), hyperactivity (HA) and impulsivity (Imp), behavioral problem (BPr) and cognitive deficit are major traits in ADHD [3, 4]. A number of co-morbid conditions like oppositional defiant disorder, conduct disorder, mood disorder, learning difficulties, etc. are also often detected in ADHD probands [5] making accurate diagnosis even more difficult.

Being a multigenic disorder, disease etiology is influenced by complex interplay between biological and environmental factors. As compared to age matched healthy

\footnotetext{
* Correspondence: kanchanmvk@yahoo.com

${ }^{1}$ Manovikas Biomedical Research and Diagnostic Centre, Manovikas Kendra, 482, Madudah, Plot I-24, Sec.-J, E.M. Bypass, Kolkata 700107, India

Full list of author information is available at the end of the article
}

children, ADHD probands often suffer from delayed maturation of the brain $[6,7]$. Maternal health during pregnancy, along with genetic and familial factors, was suggested as a variable for disease susceptibility as well as symptom severity [8]. Maternal thyroid dysfunction [9] and mental health issues also showed association with disease onset in later life. A meta-analytic study indicated almost double ADHD frequency, impaired cognitive functions, learning problems, behavioral outburst among preterm children [10]. Investigators further claimed a role of parental age in disease susceptibility [11-16]. Maternal age, birth order, peri-natal complication, and parenting, were also speculated to add up to the disease incidence [17-19]. Perinatal hypoxia, crucial factor for the well being of neurons and dopaminergic cells, was also suggested to have a primary role in ADHD [20]. Though a few researchers have explored the role of parental influences on

(c) The Author(s). 2019 Open Access This article is distributed under the terms of the Creative Commons Attribution 4.0 International License (http://creativecommons.org/licenses/by/4.0/), which permits unrestricted use, distribution, and reproduction in any medium, provided you give appropriate credit to the original author(s) and the source, provide a link to the Creative Commons license, and indicate if changes were made. The Creative Commons Public Domain Dedication waiver (http://creativecommons.org/publicdomain/zero/1.0/) applies to the data made available in this article, unless otherwise stated. 
the occurrence as well as severity of ADHD, a high range of inconsistency has been portrayed.

Several reports show that prevalence of ADHD is increasing in India [21-25]. However, in spite of appreciating a possible role of birth related variables in disease penetrance, reports from India are little scanty. Based on this lacuna, we investigated whether any pre- or post-natal factor has any influence on ADHD associated symptoms in this ethnic group.

\section{Methods}

\section{Demographic variables}

ADHD probands $(N=212)$, age $6-14$ years (M:F 189:23) were recruited following the Diagnostic and Statistical Manual-IV- Text Revised (DSM-IV TR) [26] and details of birth history as well as developmental milestones were recorded. Majority of the probands belonged to the combined subtype (73\%), while only a small number of probands were predominantly HA (12\%) and IA (15\%) subtypes.

BPr, IA, and HA was assessed by DSM-IV-TR [26] and Conner's Parent Rating Scale-Revised (CPRS-R) [27]. Impulsivity associated with interpersonal relations (Int_Per_Imp) and school work (Schl_Work_Imp) was assessed through Domain Specific Impulsivity Scale [28]. Age of onset was considered as the age when symptoms were first noticed. The study was approved by the Institutional Human Ethical committee.

\section{Inclusion/exclusion criteria}

Children diagnosed primarily with ADHD were considered for the study. Those with only psychiatric problems including pervasive developmental disorders, any form of mental retardation (IQ $\leq 70)$ and fragile-X syndrome, were excluded.

\section{Score conversion}

Order of the child was scored as 1 for the 1st child, 2 for the 2nd child and likewise. Probands with no developmental delay were grouped under 1 while those with only delayed speech was considered as 2 and with delay in motor as well as other milestones as 3 . Probands delivered normally were scored as 1 while probands delivered by caesarean section and forcep's were scored as 2 and 3 respectively. Preterm delivery was scored as 1 , full term delivery was scored as 2 and post-term deliveries were considered as 3 .

\section{Statistical analyses}

All analysis was done using the SPSS version 32. Each and every necessary assumption was checked before running the appropriate program. Principal Component analysis (PCA) was performed for the entire dataset excepting for nominal predictors like Term and Order which had low number of individuals in the third group. Initial check for sphericity and adequate sampling were done for the total dataset.

\section{Results}

Details on birth related parameters

Mean age of the probands was $(8.39 \pm 3.34)$. Average paternal age (P_Age) was 34 years $(34.14 \pm 6.19)$ while maternal age (M_Age) was 27 years $(27.04 \pm 5.26)$. Most of the probands were delivered at full term, while $20 \%$ were premature and only few were hypermatured (Fig. 1a). Analysis on birth order (Order) showed that maximum probands were the first child while second and third issues were few (Fig. 1b) and Caesarean section (C_S) was the commonest form of delivery (Fig. 1c). Only few children suffered from neonatal problems (Fig. 1d). Most of the mothers' maintained good health while few had gestational complications of hypertension, mood swings, indigestion, cold allergy, jaundice, thyroid dysfunction (Fig. 1e). Probands mostly belonged to middle to higher income groups (Fig. 1f).

\section{Principal component analysis}

Test for sphericity revealed significant insight for the dataset $(P<0.01)$. However, sampling adequacy was low $(\mathrm{KMO}=0.643)$ and hence, a preliminary analysis was performed using a varimax rotation model. The extracted communality values showed percentage of variance that could be explained by the corresponding model (Table 1). More than $60 \%$ of the variance could be explained for all the variables excepting for birth weight (B_weight) and disease onset (Onset) (Table 1). Component matrix analysis extracted the traits into 5 components (Table 2). Out of the five, the first Component included major contributions of CPRS_AI, CPRS_BPr, Int_Per_Imp, CPRS_IA, DSM_IA, Schl_Work_Imp, DSM_HA, CPRS_HA, DSM_Imp. Parental age and development (Milestones) were significant under Component 2 and 4 (Table 2). Component 4 showed moderate effects of Milestone, DSM_HA, CPRS_HA, DSM_Imp, Onset, B_weight while Component 5 exhibited effects of traits and Milestones (Table 2). After varimax rotation, Components were displaced further (Table 3). The primary component 1 included Schl_Work_Imp, DSM_IA, CPRS_IA, CPRS_AI, while parental age was included under Component 4 only (Table 3 ). Onset and Milestones came under Component 3 and Component 5 respectively (Table 3). Analysis of variance caused by each component showed more than $50 \%$ contribution by the first three Components (Additional file 1: Table S1; 27.7, 13.57, 11.36 respectively). The Scree Plot (Fig. 2) showed highest eigen value for Component 1 with higher eigen values for the 2nd and 3rd Component than the rest. Thus, it is apparent that variables involved in the first 


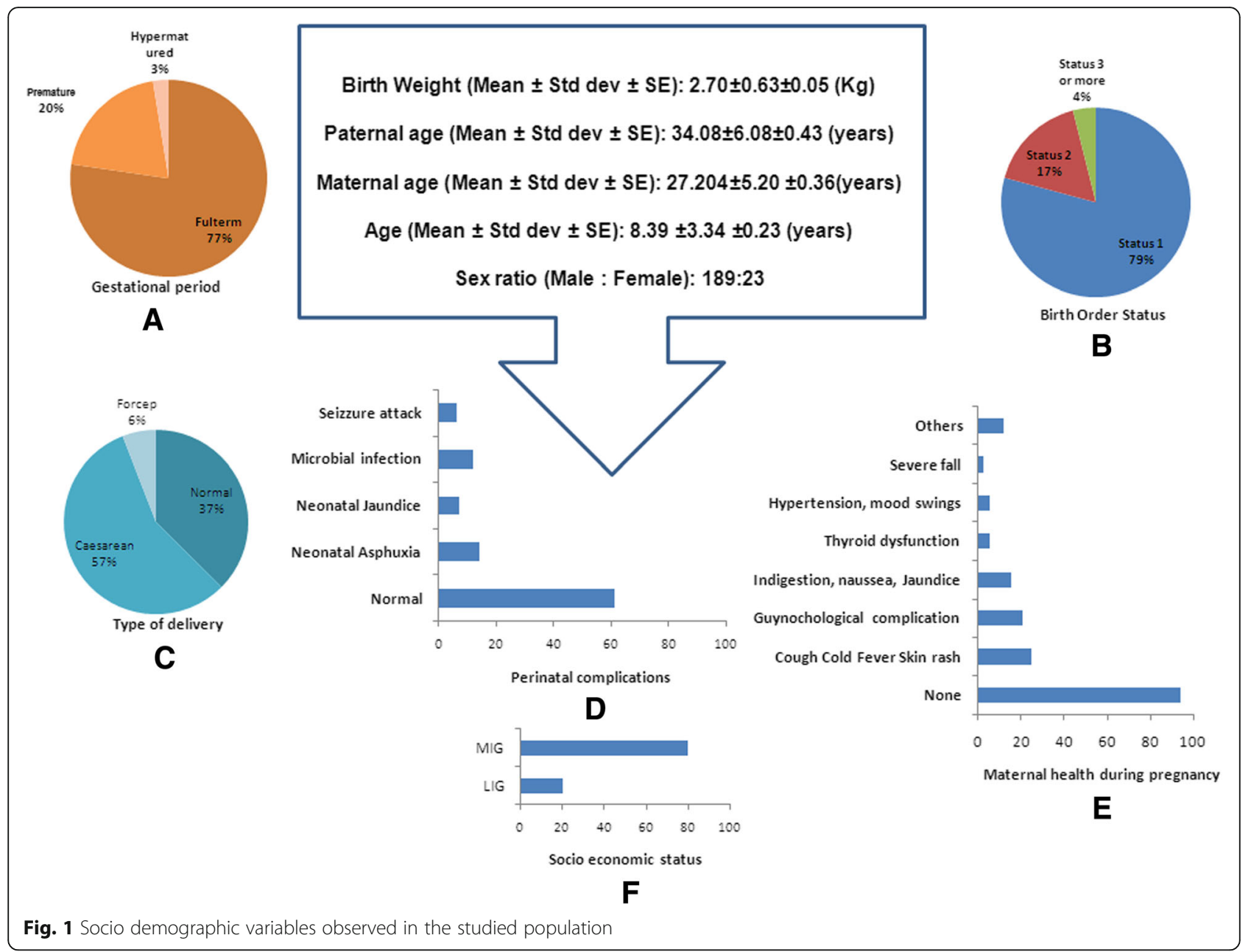

Table 1 Communalities of the variables obtained from the Varimax rotation model

\begin{tabular}{|l|r|r|}
\hline & Initial & Extraction \\
\hline P_Age & 1.000 & .804 \\
M_Age & 1.000 & .820 \\
B_weight & 1.000 & .294 \\
Milestone & 1.000 & .581 \\
Onset & 1.000 & .308 \\
CPRS_BPr & 1.000 & .886 \\
CPRS_IA & 1.000 & .808 \\
CPRS_HA & 1.000 & .711 \\
CPRS_Al & 1.000 & .874 \\
Int_Per_Imp & 1.000 & .818 \\
SchI_Work_Imp & 1.000 & .749 \\
DSM_IA & 1.000 & .777 \\
DSM_HA & 1.000 & .759 \\
DSM_Imp & 1.000 & .638 \\
\hline
\end{tabular}

three Components are significant points for the present dataset.

\section{Linear correlation analysis}

Continuous variables were analyzed by Pearson's correlation test and the ordinal variables were analyzed by Spearman Rank correlation test (significant correlations are given in Additional file 1: Table S2). Positive correlations were found for P_Age-M_age $(\mathrm{R}=0.66)$, P_Age-BPr (0.14), Order-P_Age (0.23), Order-M_Age (0.33). Onset was negatively correlated to DSM-HA ($0.19)$ and CPRS-HA (-0.16). Delivery was positively correlated with M_Age, B_weight, and Onset $(\mathrm{R}>0.13)$. DSM-HA showed negative correlation with delivery (R-0.15). Developmental milestones were negatively correlated to B_weight, CPRS_BPr, Int_Per_Imp, Schl_Work_Imp $(R>0.13)$.

\section{Multiple regression analysis}

Based on the nine outcome variables, nine different models were analyzed (Additional file 1: Table S3). Each of the models showed independence in observation in 
Table 2 Initial correlation observed between components and its corresponding variables; rotation converged in 9 iterations

\begin{tabular}{|l|c|c|c|c|c|}
\hline \multirow{2}{*}{} & \multicolumn{5}{|c|}{ Component } \\
\cline { 2 - 6 } & 1 & 2 & 3 & 4 & 5 \\
\hline CPRS_Al & .806 & & & & \\
CPRS_BPr & .749 & & & -.352 & .363 \\
Int_Per_Imp & .733 & & & -.366 & \\
CPRS_IA & .727 & -.314 & & .335 & \\
DSM_IA & .680 & & & & -.513 \\
SchI_Work_Imp & .641 & & & & -.493 \\
M_Age & & .792 & & .424 & \\
P_Age & & .791 & & .391 & \\
Milestone & & -.430 & .323 & .404 & .314 \\
DSM_HA & .380 & & .666 & & -.359 \\
CPRS_HA & .534 & & .561 & & \\
DSM_Imp & .485 & & .488 & -.381 & \\
Onset & & & -.469 & & \\
B_weight & & & -.353 & & \\
\hline
\end{tabular}

absence of multi-co linearity (Dabrin Watson [DW] 1.5$2.5,1<\mathrm{VIF}<10)$. Preliminary analysis was done including all the predictors (Term, Order, P_age, B_weight, Delivery, Milestone and Onset). But small number of subjects in the third category of Term, Order and Delivery (frequency $<0.10)$ made the models statistically weaker and these predictors were eliminated in the final step. Significant models were obtained for CPRS-BPr $(P=0.006)$ and Int_Per-Imp $(P=0.02)$. Though the overall model was not significant for DSM-AI and Schl_Work_Imp $(P>0.10)$, it

Table 3 Component matrix after Varimax rotation

\begin{tabular}{|c|c|c|c|c|c|}
\hline \multirow[t]{2}{*}{ Variables } & \multicolumn{5}{|c|}{ Rotated Component Matrix ${ }^{a}$} \\
\hline & 1 & 2 & 3 & 4 & 5 \\
\hline Schl_Work_Imp & 0.816 & & & & \\
\hline DSM_IA & 0.796 & & & & \\
\hline CPRS_IA & 0.778 & 0.353 & & & \\
\hline CPRS_Al & 0.753 & 0.473 & & & \\
\hline CPRS_BPr & & 0.903 & & & \\
\hline Int_Per-Imp & & 0.857 & & & \\
\hline DSM_HA & & & 0.856 & & \\
\hline DSM_Imp & & 0.394 & 0.683 & & \\
\hline Onset & & & 0.388 & & \\
\hline M_Age & & & & 0.896 & \\
\hline P_Age & & & & 0.885 & \\
\hline Milestone & & & & & 0.718 \\
\hline CPRS_HA & & 0.357 & 0.457 & & 0.557 \\
\hline B_weight & & & & & -0.509 \\
\hline
\end{tabular}

Extraction Method: Principal Component Analysis; Rotation Method: Varimax with Kaiser Normalization; a. Rotation converged in 9 iterations was considered further due to closely significant $\mathrm{T}$ scores (Additional file 1: Table S4; P 0.08-0.007). Positive influence of $\mathrm{P}_{-}$Age was observed on higher $\operatorname{BPr}(P=0.08)$. Higher P_Age and lower M_Age showed association with higher Int_Per_Imp $(\mathrm{P}=0.02 \& 0.04$ respectively). AI was positively influenced by higher age of onset $(P=0.06)$. BPr, Int_Per_Imp and Schl_Work_Imp showed negative correlation with developmental milestones $(P=0.08-0.007)$. No other models showed any significant correlation.

\section{T test and ANOVA}

Lower scores for $\operatorname{BPr}(P=0.02)$ and $\mathrm{AI}(P=0.052)$ were noticed in the preterm as compared to full term children (Table 4). Normally developing probands exhibited higher score for BPr, Int_Per_Imp (8.02 \pm 3.22$)$ and Schl_Work_Imp $(6.77 \pm 2.87)$ as compared to those exhibiting developmental delay (Table 4). Values remained unaltered even after post-hoc analysis following ANOVA $(P<0.05)$.

\section{Discussion}

Decades of research has established a firm neuro-psychological basis for ADHD, though the actual remediation is still far away. Two central neuro-psychological models were hypothesized [1]. The first one is the executive or top down model indicating ADHD as a disorder of executive dysfunction affecting goal directed self organized flexible actions. The other theory is bottom up sensory/reward theory which suggest that ADHD patients lack motivation, reward and emotional regulation [1]. A combination of these two models gave rise to an integrated model portraying a complex clinical scenario. However, ADHD symptoms are highly 


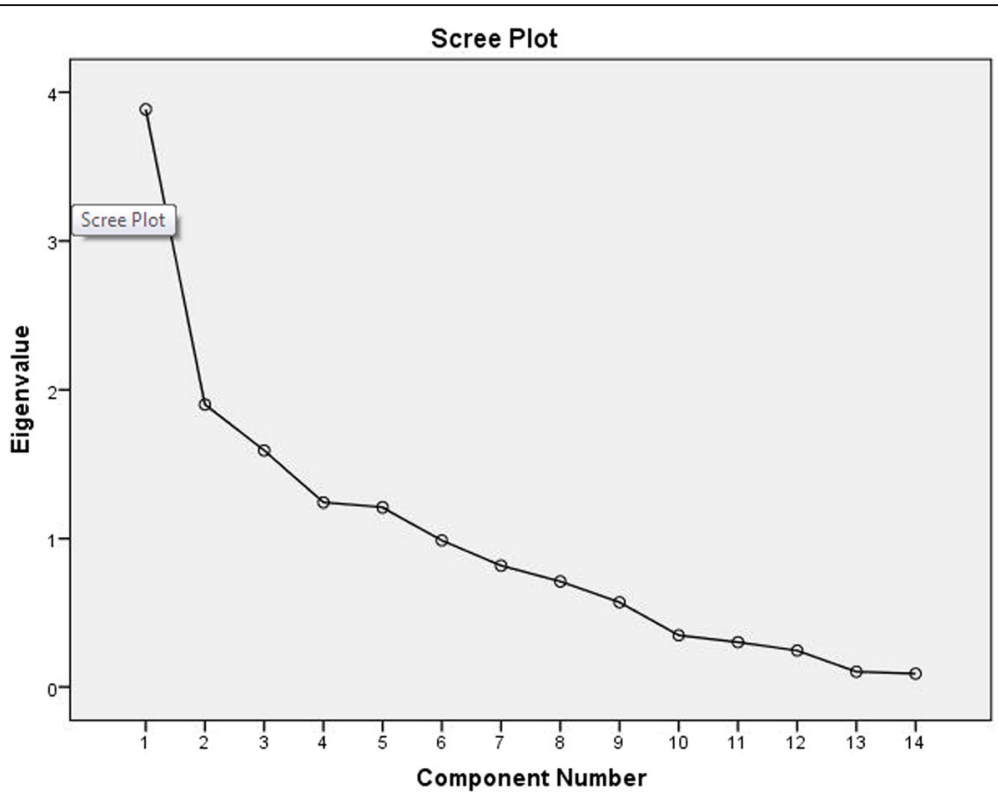

Fig. 2 Scree plot of eigen value for corresponding component

heterogeneous and every domain of impairment may add up to a new level of complexity, making proposition of any individual model difficult [29-31].

In India, prevalence of ADHD was reported to be $11.33 \%$ among primary school children [22], 7.2\% among adolescents [23], and 5.48\% among college students [24]. However, detailed report on birth histories and their possible influence on the symptom severity were less frequently studied. Here, we report for the first time a role of birth related factors in the symptom severity of Indian ADHD probands. Significant influence of parental age, B_weight, delivery process, age of onset and

Table 4 Comparative analysis on means

\begin{tabular}{lllll}
\hline Symptom & Variable & Mean \pm SDev & T test P & Posthoc P \\
\hline BPr & Pre Term & $6.35 \pm 5.16$ & 0.02 & NA \\
& Full term & $8.80 \pm 5.36$ & & \\
Al & Pre Term & $23.33 \pm 7.73$ & 0.052 & NA \\
& Full term & $25.96 \pm 6.34$ & & \\
BPr & Normal & $9.32 \pm 5.45$ & 0.0001 & 0.001 \\
& Global & $5.74 \pm 4.91$ & & \\
Int_Per_Imp & Normal & $8.02 \pm 3.22$ & 0.004 & 0.01 \\
& Global & $6.45 \pm 2.30$ & & \\
Schl_Work_Imp & Normal & $6.77 \pm 2.87$ & 0.02 & 0.056 \\
& Global & $5.67 \pm 2.74$ & & \\
DSM_IA & Normal & $12.10 \pm 4.73$ & 0.064 & 0.14 \\
& Global & $10.63 \pm 4.24$ & & \\
Al & Normal & $25.01 \pm 6.29$ & 0.065 & 0.17 \\
& Speech & $27.71 \pm 6.66$ & & \\
\hline
\end{tabular}

developmental milestones were noticed on the trait scores. Based on the significant correlations detected amongst the predictable variables, we present a schematic diagram to understand the trajectory (Fig. 3). Parental age was identified as the principal independent factor. B_weight and term of delivery were not influenced by parental age, though the two were correlated amongst themselves. Thus, we have put birth term as another primary variable along with B_weight. After this primary level, three intermediate levels became evident. Birth order, being influenced by parental age was placed as the first intermediate variable. Process of delivery was the next in the same level; it was related to M_Age and B_weight. Milestone was also placed in the same level as it was influenced by the primary predictor B_weight. Since age of onset was only related to the delivery procedure, it was placed at the next intermediate level. Finally multiple regressions led to the isolation of multi- influential predictors that modified the symptom scores. All the predictor variables excepting the birth order and term were found to influence the symptoms and so the path diagram originated from Parental age, and ended in different trait scores traversing through birth weight, birth order, delivery procedure, developmental milestones and age of onset.

Studies from the western countries revealed a relationship between lower maternal age and higher vulnerability to ADHD [12-14]. Investigators also proposed association of lower maternal age with symptom intensity [11-16] and parenting was suggested to be better by older mothers [32]. Association between higher oppositional behavior as well as HA /Imp score of ADHD probands and higher maternal age were also reported [15]. 


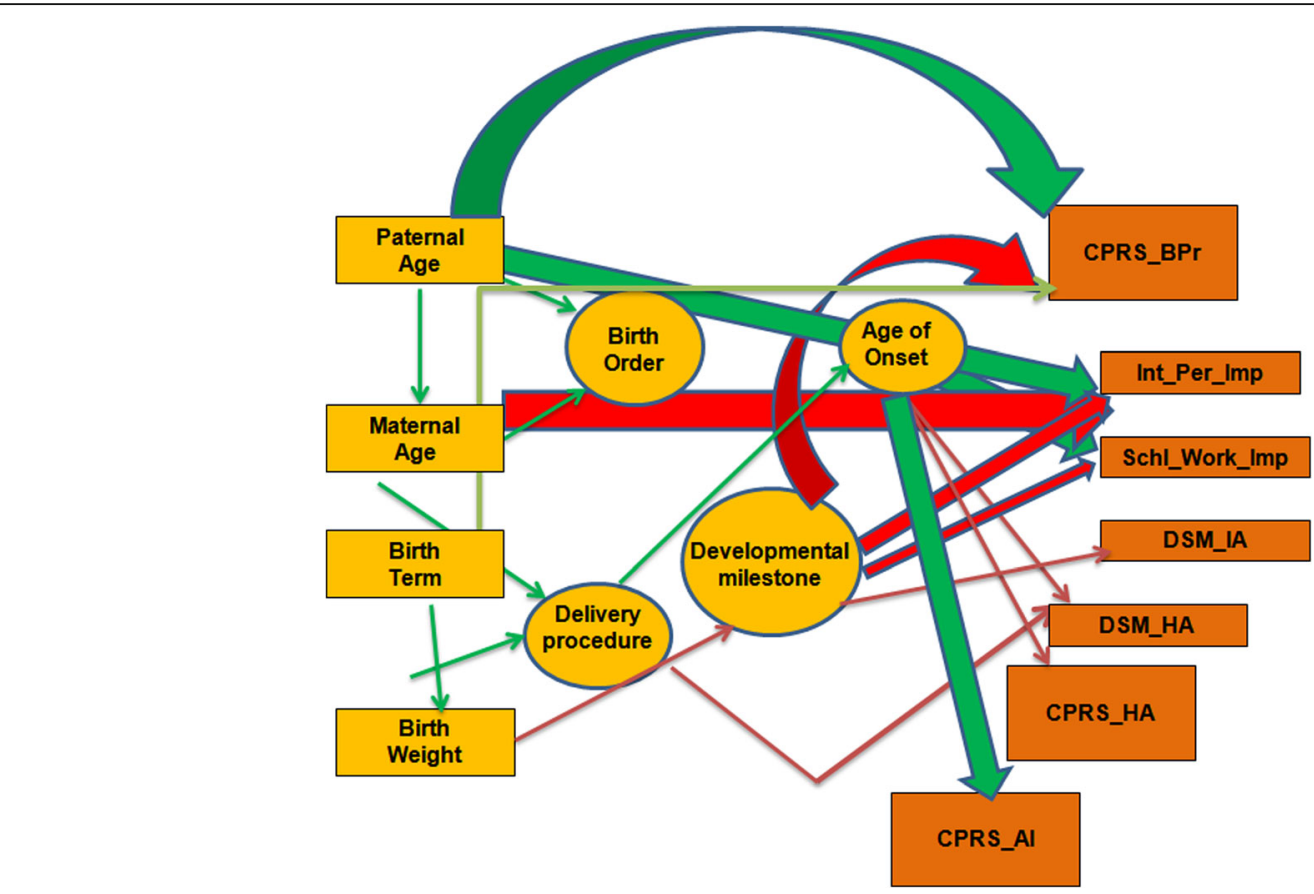

Fig. 3 Manual path diagram to understand relation between different variables

However, effect of paternal age was not evident in Danish patients [13]. Our analysis revealed negative influence of maternal age on the Imp of probands; individuals born to younger mothers were more impulsive. Furthermore, higher paternal age was related to higher scores for BPr and Imp. We assume that these inconsistencies in associations may result from age differences, variation in sample size or a confounded effect of socio-demographic variations warranting further investigation.

A recent study from the Finland suggested association between low Apgar score and C_S with higher risk of ADHD [33]. We found correlation between higher maternal age and Caesarean/forcep delivery, associated with lower HA. Whether this contradictory finding is due to the presence of an actual socio-demographic difference warrants further in depth analysis in large cohort.

In the Caucasoid population, birth weight was speculated as a prime risk factor for developing ADHD symptoms, primarily inattention $[30,34-36]$. In the Indo-Caucasoid population, we have noticed substantial influence of B_weight on the delivery process and developmental milestones which were associated further with symptom scores; preterm children showed lower score for BPr/AI. It can be speculated that B_weight showing negative association with developmental delay could be a marker for overall development and along with various intermediate factors, may affect ADHD associated traits.

Earlier investigators reported delay in motor development of ADHD probands [37]. Our study group showed delayed motor development in $26 \%$ probands. However, interestingly it showed negative influence on BPr; children with developmental delay exhibited reduced Imp. In an MRI based study on the developmental chronology of healthy brain, it was found that the affect and reward processing circuitry involving amygdale and nucleus accumbens develop faster than the cognitive control domain [38]. Nucleus accumbens, important for emotional circuitry, also has a role in motor control. Thus, it may be hypothesized that developmental delay in these regions may interfere with affective behavior as well as motor response while balancing the delayed cortical maturation, as reported in ADHD earlier [6]. However, the observed effect of delayed motor development on reduced impulsivity may also be partly due to seeking professional help at an early age. Our earlier study showed higher HA in the late onset group [39]. The present study revealed influence of late onset on increased AI and gradual decrease in HA on a continuous scale, indicating necessity of further analysis in larger cohort.

\section{Conclusion}

Bio-demographic factors may assist in understanding the disease more clearly thereby providing chances for better rehabilitation. In an earlier study, we have reported that ADHD probands sustain impairment in attention while organizational efficiency improves with time and those with learning difficulties exhibit even more scholastic backwardness [40]. Our current analysis on the same group of probands suggests that parental age, low birth 
weight, and delivery process may affect symptom severity of ADHD probands, a finding which could be useful for monitoring growth of a child leading to early intervention. However, our number of subjects was limited. Successful replication in larger cohort and proper attention to birth related/ developmental factors may widen a contemporary window to provide more efficient management of ADHD related symptom severity.

\section{Additional file}

Additional file 1: Table S1. Total variance explained by the principal components in the total data set. Table S2. Analysis of Correlation between identified variables. Table S3. Summary of multiple regression analysis. Table S4. Details of multiple regression analysis. (DOCX $41 \mathrm{~kb}$ )

\section{Abbreviations}

ADHD: Attention deficit hyperactivity disorder; Al: ADHD index; B_weight: Birth weight; BPr: Behavioral problem; C_S: Caesarian section; CPRS_BPr: Behavioral problem assessed by CPRS-R; CPRS-Al: ADHD index scored by CPRS-R; CPRS-HA: Hyperactivity scored by CPRS-R; CPRSIA: Inattention scored by CPRS-R; CPRS-Imp: Impulsivity scored by CPRS-R CPRS-R: Conners' Parents rating scale revised; Delivery: Term of delivery; DSM-HA: Hyperactivity scored by DSM-IV-TR; DSM-IA: Inattention scored by DSM-IV-TR; DSM-Imp: Impulsivity scored by DSM-IV-TR; DSM-IV-TR: Diagnostic and Statistical Manual of Mental Disorders-4th edition-text revised; HA: Hyperactivity; IA: Inattention; Imp: Impulsivity; Int_Per_Imp: Interpersonal impulsivity; M_age: Maternal age; Milestones: Developmental milestones; Onset: ADHD symptom onset; Order: Birth order; P_Age: Paternal age; PCA: Principal component analysis; Schl_Work_Imp: School work impulsivity

\section{Acknowledgements}

Authors are thankful to Dr. S Sinha and Dr. A Ray for recruitment of patients for ongoing research activities. We are also acknowledging Ms. M Chatterjee for assistance in data handling and all the participants for their voluntary involvement in the study. The study was sponsored by the Manovikas Kendra, Kolkata, India.

\section{Funding}

This study was sponsored by Manovikas Kendra Rehabilitation and Research Institute for the Handicapped, Kolkata, which aided in study subject recruitment from the Centre for Assessment and Therapy, Manovikas Kendra. Both the authors are engaged in the Biomedical Research and Diagnostic Centre (BRDC) of Manovikas Kendra and have collected demographic details from the BRDC database for analysis and interpretation of data.

\section{Availability of data and materials}

Data not pertaining to individual patients will be available from the corresponding author upon reasonable request. Any other information will be shared based on the ethical clearance.

\section{Authors' contributions}

SM conceptualized the work, performed data as well as statistical analysis and drafted the manuscript. KM supervised its execution and edited the manuscript. Both the authors approved the final manuscript.

\section{Ethics approval and consent to participate}

Approval from the Institutional Human Ethical Committee was obtained for recruitment of $\mathrm{ADHD}$ probands following the guidelines of the Indian Council of Medical Research (PR-002-10). Blood samples were collected after obtaining informed written consent for participation from the parents/care givers.

\section{Consent for publication}

Not applicable.

\section{Competing interests}

None to declare.

\section{Publisher's Note}

Springer Nature remains neutral with regard to jurisdictional claims in published maps and institutional affiliations.

\section{Author details}

${ }^{1}$ Manovikas Biomedical Research and Diagnostic Centre, Manovikas Kendra, 482, Madudah, Plot I-24, Sec.-J, E.M. Bypass, Kolkata 700107, India. ${ }^{2}$ Present address: Mahidol University, Salaya, Thailand.

Received: 3 December 2018 Accepted: 2 April 2019

Published online: 22 April 2019

\section{References}

1. Matthews M, Nigg JT, Fair DA. Attention deficit hyperactivity disorder. Curr Top Behav Neurosci. 2014;6:235-66.

2. Wilens TE, Spencer TJ. Understanding attention deficit hyperactivity disorder from childhood to adulthood. Postgrad Med. 2010;122(5):97-109.

3. Brown TE. Executive functions and attention deficit hyperactivity disorder: implications of two conflicting views. New Heaven: Yale University Press; 2007

4. Barkley RA. Distinguishing sluggish cognitive tempo from ADHD in children and adolescents: executive functioning, impairment, and comorbidity. J Clin Child Adolesc Psychol. 2012:42:161-73.

5. American Psychiatric Association. Diagnostic and statistical manual of mental disorders. 5th ed. Washington, DC: American Psychiatric Association; 2013.

6. Shaw P, Eckstrand K, Sharp W, Blumenthal J, Lerch JP, Greenstein D, et al. Attention-deficit/hyperactivity disorder is characterized by a delay in cortical maturation. Proc Nat Acad Sci. 2007;104:19649-54.

7. Zhu Y, Yang D, Ji W, Huang T, Xue L, Jiang $X$, Chen L, Wang F. The relationship between Neurocircuitry dysfunctions and attention deficit hyperactivity disorder: a review. Bio Med Res Int. 2016. https://doi.org/10. 1155/2016/3821579.

8. Okano L, Ji Y, Riley AW, Wang X. Maternal psychosocial stress and children's ADHD diagnosis: a prospective birth cohort study. J Psychosom Obstet Gynaecol. 2018;23:1-9. https://doi.org/10.1080/0167482X.2018.1468434.

9. Fetene DM, Betts KS, Alati R. Mechanisms in endocrinology: maternal thyroid dysfunction during pregnancy and behavioral and psychiatric disorders of children: a systematic review. Eur J Endocrinol. 2017;177(5): R261-73. https://doi.org/10.1530/EJE-16-0860.

10. Allotey J, Zamora J, Cheong-See F, Kalidindi M, Arroyo-Manzano D, Asztalos $E$, et al. Cognitive, motor, behavioral and academic performances of children born preterm: a meta-analysis and systematic review involving 64 061 children. Brit J Obstet Gyneacol. 2018;125(1):16-25. https://doi.org/10. 1111/1471-0528.14832.

11. Gillberg C, Rasmussen P, Wahlström J. Minor neurodevelopmental disorders in children born to older mothers. Dev Med Child Neurol. 1982;24(4):437-47.

12. Chudal R, Joelsson P, Gyllenberg D, Lehti V, Leivonen S, Hinkka-Yli-Salomäki S, Gissler M, Sourander A. Parental age and the risk of attention-deficit/ hyperactivity disorder: a nationwide, population-based cohort study. J Am Acad Child Adolesc Psychiatr. 2015;54(6):487-94. https://doi.org/10.1016/j. jaac.2015.03.013.

13. Mikkelsen HS, Olsen J, Bech BH, Obel C. Parental age and attentiondeficit/hyperactivity disorder (ADHD). Int J Epidemiol. 2017;46(2):409-20. https://doi.org/10.1093/ije/dyw073.

14. Silva D, Colvin L, Hagemann E, Bower C. Environmental risk factors by gender associated with attention-deficit/hyperactivity disorder. Pediatrics. 2014;133(1):e14-22. https://doi.org/10.1542/peds.2013-1434.

15. Ghanizadeh A. Association of ADHD symptoms severity with higher paternal and lower maternal age of a clinical sample of children. Acta Med Iran. 2014:52:49-51.

16. Pohlabeln H, Rach S, De Henauw S, Eiben G, Gwozdz W, Hadjigeorgiou C, et al. Further evidence for the role of pregnancy-induced hypertension and other early life influences in the development of ADHD: results from the IDEFICS study. Eur Child Adolesc Psychiatr. 2017;26(8):957-67. https://doi. org/10.1007/s00787-017-0966-2.

17. Chang Z, Lichtenstein P, D'Onofrio BM, Almqvist C, Kuja-Halkola R, Sjölander A, Larsson $\mathrm{H}$. Maternal age at childbirth and risk for ADHD in offspring: a 
population-based cohort study. Int J Epidemiol. 2014;43(6):1815-24. https:// doi.org/10.1093/ije/dyu204.

18. Bora S, Pritchard VE, Chen Z, Inder TE, Woodward LJ. Neonatal cerebral morphometry and later risk of persistent inattention/hyperactivity in children born very preterm. J Child Psychol Psychiatr. 2014;55(7):828-38. https://doi.org/10.1111/jcpp.12200.

19. Kok R, Thijssen S, Bakermans-Kranenburg MJ, Jaddoe WW, Verhulst FC, White $\mathrm{T}$, van IJzendoorn $\mathrm{MH}$, Tiemeier $\mathrm{H}$. Normal variation in early parental sensitivity predicts child structural brain development. J Am Acad Child Adolesc Psychiatr. 2015;54(10):824-31. https://doi.org/10. 1016/j.jaac.2015.07.009.

20. Giannopoulou I, Pagida MA, Briana DD, Panayotacopoulou MT. Perinatal hypoxia as a risk factor for psychopathology later in life: the role of dopamine and neurotrophins. Hormones (Athens). 2018;17(1):25-32. https://doi.org/10.1007/s42000-018-0007-7.

21. Arora NK, Nair MKC, Gulati S, Deshmukh V, Mohapatra A, Mishra D, et al. Neurodevelopmental disorders in children aged 2-9 years: population-based burden estimates across five regions in India. PLoS Med. 2018;15(7): e1002615. https://doi.org/10.1371/journal.pmed.1002615.

22. Venkata JA, Panicker AS. Prevalence of attention deficit hyperactivity disorder in primary school children. Ind J Psyc. 2013;55(4):338-42.

23. Juneja M, Sairam S, Jain R. Attention deficit hyperactivity disorder in adolescent school children. Indian Pediatr. 2014;51(2):151-2.

24. Jhumbh I, Arun P, Garg J. Cross-sectional study of self-reported ADHD symptoms and psychological comorbidity among college students in Chandigarh, India. Ind Psychiatr. 2014;23(2):111-6.

25. Jaisoorya TS, Beena KV, Beena M. Prevalence and correlates of self-reported ADHD symptoms in children attending school in India. J Atten Disord. 2016: 1-5. https://doi.org/10.1177/1087054716666951.

26. American Psychiatric Association. Diagnostic and statistical manual of mental disorders. 4th ed-text revised. Washington, DC; 2000.

27. Conners CK, Sitarenios G, Parker JD, Epstein JN. The revised Conners' parent rating scale (CPRS-R): factor structure, reliability, and criterion validity. J Abnorm Child Psychol. 1998;26:257-68.

28. Tsukuyama E, Lee A, Kim B. Domain-specific impulsivity in school-age children. Dev Sci. 2013;16(6):879-93.

29. Mil J, Petronis A. Pre- and peri-natal environmental risks for attention deficit hyperactivity disorder (ADHD): the potential role of epigenetic processes in mediating susceptibility. J Child Psychol Psychiatr. 2008;49(10):1020-30.

30. van Mil NH, Steegers-Theunissen RP, Bouwland-Both MI, Verbiest MM, Rijlaarsdam J, Hofman A, et al. DNA methylation profiles at birth and child ADHD symptoms. J Psychiatr Res. 2014;49:51-9. https://doi.org/10.1016/j. jpsychires.2013.10.017.

31. Thapar A, Cooper M. Attention deficit hyperactivity disorder. Lancet. 2016; 387:1240-50. https://doi.org/10.1016/S0140-6736(15)00238-X.

32. Geronimus AT, Korenman S, Hillemeier MM. Does young maternal age adversely affect child development? Evidence from cousin comparisons in the United States. Pop Develop Rev. 1994;20:585-609. https://doi.org/10. 2307/2137602

33. Sucksdorff M, Lehtonen L, Chudal R, Suominen A, Gissler M, Sourander A. Lower Apgar scores and caesarean sections are related to attention-deficit/ hyperactivity disorder. Acta Paediatr. 2018;107:1750-8. https://doi.org/10. 1111/apa.14349.

34. Momany AM, Kamradt JM, Ullsperger JM, Elmore AL, Nigg JT, Nikolas MA. Sex moderates the impact of birth weight on child externalizing psychopathology. J Abnorm Psychol. 2017;126(2):244-56. https://doi.org/10. 1037/abn0000238.

35. Franz AP, Bolat GU, Bolat H, Matijasevich A, Santos IS, Silveira RC, Procianoy RS, Rohde LA, Moreira-Maia CR. Attention-deficit hyperactivity disorder and very preterm/very low birth weight: a meta-analysis. Pediatrics 2018; 141(1): pii: e20171645. doi: https://doi.org/10.1542/peds.2017-1645.

36. Pettersson E, Sjölander A, Almqvist C, Anckarsäter H, D'Onofrio BM, Lichtenstein $\mathrm{P}$, Larsson $\mathrm{H}$. Birth weight as an independent predictor of ADHD symptoms: a within-twin pair analysis. J Child Psychol Psychiatr. 2015; 56(4):453-9. https://doi.org/10.1111/jcpp.12299.

37. Rosa Neto F, Goulardins JB, Rigoli D, Piek JP, Oliveira JA. Motor development of children with attention deficit hyperactivity disorder. Rev Bras Psiquiatr. 2015; 37(3):228-34. https://doi.org/10.1590/1516-4446-2014-1533.

38. Mills KL, Goddings AL, Clasen LS, Giedd JN, Blakemore SJ. The developmental mismatch in structural brain maturation during adolescence. Dev Neurosci. 2014;36:147-60. https://doi.org/10.1159/000362328.
39. Maitra S, Sarkar K, Sinha S, Mukhopadhyay K. The dopamine receptor D5 may influence age of onset: an exploratory study on indo-Caucasoid ADHD subjects. J Child Neurol. 2016;31:1250-6.

40. Maitra S, Mukherjee K, Chatterjee M, Karmakar A, Sinha S, Mukhopadhyay K. Pilot study revealed association of DRD4 promoter variants with ADHD associated functional deficit in Indian probands. Global J Med Res. 2016; 6(2A):9-20. ISSN: 2249-4618.

\section{Ready to submit your research? Choose BMC and benefit from:}

- fast, convenient online submission

- thorough peer review by experienced researchers in your field

- rapid publication on acceptance

- support for research data, including large and complex data types

- gold Open Access which fosters wider collaboration and increased citations

- maximum visibility for your research: over $100 \mathrm{M}$ website views per year

At BMC, research is always in progress.

Learn more biomedcentral.com/submissions 